\title{
Mapping the geometry of volcanic systems with magnetotelluric soundings: Results from a land and marine magnetotelluric survey performed during the 2018-2019 Mayotte seismovolcanic crisis
}

\author{
Darnet M. ${ }^{1,{ }^{\star}}$, Wawrzyniak P. ${ }^{1}$, Tarits Pascal ${ }^{2,3,4}$, Hautot S. ${ }^{3}$, D'Eu J.F. ${ }^{4}$
}

\author{
${ }^{1}$ BRGM, Bureau des Recherches Géologiques et Minières, 3 av. Claude-Guillemin, BP 36009, 45060 \\ Orléans Cedex 2, France \\ 2 IUEM, Institut Universitaire Européen de la Mer, LGO, UMR 6538 - IUEM/UBO, Place Nicolas \\ Copernic, Plouzané, 29280, France \\ 3 IMAGIR Sarl, Tech-Iroise, ZA de Mespaol 2, 1 rue des Ateliers, 29290 Saint Renan,France \\ ${ }^{4}$ MAPPEM Geophysics SAS, Marine Electromagnetic Investigation, Batiment Tech-Iroise, 1 rue des \\ Ateliers, Zone de Mespaol, 29290 Saint-Renan, France \\ * Corresponding author : M. Darnet, email address : $\underline{\text { m.darnet@brgm.fr }}$ \\ p.wawrzyniak@brgm.fr ; pascal.tarits@univ-brest.fr ; sophie.hautot@imagir.eu ; \\ j.deu@mappem-geophysics.com
}

\begin{abstract}
:
A major seismovolcanic crisis has afflicted the islands of Mayotte, Comoros Archipelago, since May 2018, although the origin is debated. Magnetotellurics (MT), which is sensitive to hydrothermal and/or magmatic fluids and can map the subsurface electrical resistivity structure, can provide insight by revealing the internal structure of the volcanic system. In this paper, we report the results of a preliminary land and shallow marine MT survey performed on and offshore the island nearest the crisis. The 3D inversionderived electrical resistivity model suggests that the island is underlain by a shallow $\sim 500$-m-thick conductive layer atop a deeper, more resistive layer, possibly associated with a high-temperature geothermal system. At depths of $\sim 15 \mathrm{~km}$, the resistivity drops by almost two orders of magnitude, possibly due to partial melting. Further petrophysical and geophysical studies are underway for confirmation and to map the geometry and evolution of the volcanic system.
\end{abstract}




\section{Highlights}

- A major seismovolcanic crisis has afflicted the islands of Mayotte, Comoros Archipelago, since May 2018 , although the origin is debated. We report the results of a preliminary land and shallow marine MT survey performed on and offshore the island nearest the crisis. The 3D inversion-derived electrical resistivity model suggests that the island is underlain by a shallow $\sim 500$-m-thick conductive layer atop a deeper, more resistive layer, possibly associated with a high-temperature geothermal system. At depths of $\sim 15 \mathrm{~km}$, the resistivity drops by almost two orders of magnitude, possibly due to partial melting.

Keywords : magnetotelluric, electrical resistivity, seismovolcanic, geothermal 


\section{Introduction}

Mayotte, located along a WNW-ESE oceanic ridge at the boundary of the Lwandle and Somalian plates, represents a region of islands within the volcanic Comoros Archipelago north of the Mozambique Channel between the northern tip of Madagascar and the eastern coast of Mozambique. The region of Mayotte is composed predominantly of two main islands, namely, Grande Terre $\left(363 \mathrm{~km}^{2}\right)$ to the west and Petite Terre $\left(11 \mathrm{~km}^{2}\right)$ to the east (figure 1).

In May 2018, an offshore seismovolcanic crisis initiated approximately $50 \mathrm{~km}$ to the east of Mayotte; the crisis included the largest seismic event ever recorded in the Comoros with a Mw=5.9 (Lemoine et al., 2019; Cesca et al., 2020), and an estimated $5 \mathrm{k}^{{ }^{*}{ }_{1}{ }^{3}}$ ol 'ava was released from an eruptive site in the same area (REVOSIMA bulletin, http://w $\ldots{ }^{1} \mathrm{vz} \rho$.fr/fr/actualites-reseau). The seismicity subsequently migrated to the west and is now ' 'camu between 5 and $15 \mathrm{~km}$ from the Petite Terre (figure 1). The possible causes of the Ccr lor s volcanism continue to constitute a topic of controversy (Lemoine et al., 2019), as its orioi: couid be related to i) the presence of a hot spot (Emerick and Duncan, 1982), ii) lithospl e ractures (Nougier et al., 1986), or iii) a combination of the two, i.e., regional ex ens on in conjunction with asthenospheric processes (Debeuf, 2004; Michon, 2016). Fore rasts ru jarding the evolution of this crisis remain very uncertain and require the gathering of ${ }^{\top}{ }^{\top} \mathrm{d}$ li ional geoscientific data, particularly geophysical data, to help understand the internal stru, $\mathrm{rr}_{\mathrm{i}} ;$ the corresponding volcanic system.

Magnetotellurics (MT) is a geophysical method commonly used to generate electrical resistivity images of the suhsur ' 7 ce. By combining long-period ( $>1 \mathrm{~s}$ ) fluctuations of natural electric and magnetic fiel is, $\perp$ T analysis can infer the electrical resistivity structure of the Earth at depths reaching several ' ns of kilometers (Chave and Jones, 2012). However, this technique suffers one major drawback: its sensitivity to anthropic noise, which can obfuscate signals of interest (Junge, 1996). Accordingly, robust data processing methods have been developed to reduce the influence of such noise (Chave and Thomson, 2004; Egbert, 2002).

At temperatures lower than $<500-800^{\circ} \mathrm{C}$, the electrical resistivity of saturated volcanic rock depends strongly on the physical and chemical properties of the fluid filling the pore space and on the presence of alteration minerals (Revil et al., 1998; Nono et al., 2018). At higher temperatures, intramineral conduction mechanisms dominate, and upon reaching the solidus temperature, the presence of melt significantly influences the rock electrical resistivity (Laumonier et al., 2017). Therefore, measurements of electrical resistivity can help assess the presence of 
hydrothermal and/or magmatic fluids. This sensitivity explains why MT is commonly used in geothermal exploration (Spichak and Manzella, 2009) and volcano imaging (Ingham et al., 2009). MT has also recently been applied to monitor resistivity changes in volcanoes (Aizawa et al., 2013; Wawrzyniak et al., 2017; Ladanivskyy et al., 2018). However, the application of time-lapse MT continues to be challenging due to variations in geomagnetic activity, sources of anthropic noise and the stability of the MT setup (Abdelfettah et al., 2018).

In this paper, we present the results of an land and shallow marine MT survey carried out during the seismovolcanic crisis of Mayotte. The main challenge associated with performing MT measurements on this island was the presence of strong anthropic in ise and the small size of the island; accordingly, both land and shallow marine data had to $b \cdot a c$ uired. The data quality was ultimately good over a wide period range (from $0.01 \mathrm{~s}$ to 1700 s), providing the opportunity to

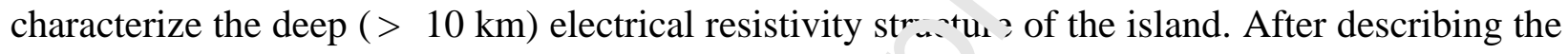
MT field setup, we present the processed MT data . . d the results from a 3D inversion. Furthermore, we discuss both the quality of the dat with a time-lapse MT analysis and the resolution of the resistivity model with a ser ; ivitv study. Finally, we conclude with a discussion of possible explanations for the observed el - rical resistivity anomalies.

\section{MT data acquisition aid processing}

\subsection{Land MT survey}

Due to its high degree of uru ni ation (e.g., airports, power plants, military bases), Petite Terre island presents a cha1 ${ }^{\prime} n_{e}{ }^{-i n s}$ environment in which to perform passive electromagnetic (EM) measurements. To miticat the impacts of ambient EM noise on the MT soundings, we deployed two MT stations on the most isolated parts of the island (sites L1 and L2) and one remote reference MT station on Grande Terre island (site L0), approximately $15 \mathrm{~km}$ away from Petite Terre (figure 1). We used ADU07 systems ( Metronix, Germany) with unpolarizable $\mathrm{Pb}-\mathrm{PbCl}_{2}$ electrodes (Wolf Ltd, Hungary) and MSF07 magnetic coils (Metronix, Germany). The sensors were oriented toward the north and east ( $\mathrm{x}=$ north, $\mathrm{y}=$ east). MT recordings were performed synchronously for 4 days at both sites.

We processed the time series following the robust approach of Chave and Thomson (2004) with a remote reference MT station. We computed the full impedance tensor at each site at periods 
ranging from 0.001 to $1000 \mathrm{~s}$. An MT sounding example is shown in figure 2. Overall, the data were of good quality over the period range; however, at 1-10 s, noise could not be excluded due to the weakness of the primary field. The phase tensor ellipses shown in figure 1 were extracted from the phase tensors calculated using the formula of Booker (2014).

\subsection{Marine MT survey}

Because of the limited number of sites favorable for MT measurements on Petite Terre island, we deployed four new-generation low-power shallow marine MT s'stems (STATEM) around the island at water depths ranging from 15 to $25 \mathrm{~m}$ (figure 1). These लT A : EM systems were recently developed by MAPPEM Geophysics and the Ocean Geoscipn ‘ _aboratory (LGO), European Institute for Marine Studies (IUEM). Each STATEM sy $\ldots$ m records the two horizontal components of the electric field with 5m-long electric di pols s and marine $\mathrm{Ag}-\mathrm{AgCl}$ electrodes. The three components of the magnetic field were ohtinned rom a 3-component fluxgate sensor. With an optimized datalogger, the measuremer is ve e performed synchronously with the land stations for 2 days at a sampling rate of $512 \mathrm{~Hz}$ The design of the system is such that motion of the system induced by oceanic current is minı.ized. During the survey, bidirectional tiltmeter measurements performed every secon $\%$ ho ,ed that motion and drift of the sensor were minimum (less than $+/-0.2 \mathrm{deg}$ ).

Similarly to the land case, he time series were robustly processed with the bounded influence, remote reference pre essing (BIRRP) code of Chave and Thomson (2004). The processing of shallow ma ine MT data is a challenging task due to the high level of ocean-induced EM noise that can mask tre MT signal. For the electric field, noise can be generated not only by the movement of the water layer (e.g., waves, swells, tides) within the Earth's magnetic field but also by the current-induced motion of the electrodes. Similarly, magnetic field measurements can become contaminated by noise associated with not only ocean-induced electric currents but also the motion of the sensor. As a consequence, both electric and magnetic measurements may exhibit high levels of ocean-induced EM noise that is well correlated and difficult to distinguish from the MT signal. Therefore, the use of a land remote reference is of paramount importance to reduce the impacts of ocean-induced noise (figure S1). Remote referencing between marine sites was sufficient at long periods ( $>100 \mathrm{~s}$ ); hence, the challenge was to obtain the MT impedance at the shortest possible period $(<0.1 \mathrm{~s})$. Depending on the type of noise, magnetic and/or electric field 
measurements from the remote reference were used to filter out oceanic noise. An example of the MT transfer function is shown in figure 2. Despite the lack of high-frequency measurements ( < $0.01 \mathrm{~s}$ ) due to the weakness of the MT signals recorded beneath $\sim 20 \mathrm{~m}$ of seawater, the MT transfer function was reliably recovered over the $0.02-1000 \mathrm{~s}$ period band and was consistent with the nearby land site (site L2) (figure 2). Nevertheless, similar to the land data, the MT impedance results at 1-10 s were not reliable, as this period range is further impacted by a high level of swell-induced noise.

\subsection{Permanent land MT monitoring}

Given the good quality of the MT recordings at site L2, tho szup was adapted to perform long-term monitoring of the MT impedance tensor (e.g., he sioles and recording device were buried). The objective was to to test the feasibility of rec rding possible resistivity changes at depth related to the seismovolcanic crisis. Permanent reasu "ements of the horizontal components of the electric and magnetic fields began on May $2 ?, 2,19$. Every four days, the impedance tensor was computed for a comparison with th - in itiai MT results. The time-lapse MT data were processed with a in-house developed open-su rce Python library (Smai and Wawrzyniak, 2020) using the bounded influence processirs 1. athod of Chave and Thomson (2004) in a two-stage remote reference configuration.

The time-lapse MT impe lan $\sim$ results from May $29^{\text {th }}$ to June $28^{\text {th }}$ are presented in figure 3. We observed that the $\mathrm{Kp}$ geomagnetic index (https://www.swpc.noaa., ov/, roducts/planetary-k-index) strongly varied during this period (figure 3a). The most cu tinuous MT soundings (apparent resistivity, phase and phase tensor diagrams) were obtained for the four-day intervals beginning on May $29^{\text {th }}$ and June $12^{\text {th }}$, when the $\mathrm{Kp}$ index remained high (figure $3 \mathrm{~b}$ and c). Unfortunately, site L2 is located in a relatively dry area of Mayotte, and the ground surrounding the electrodes became progressively dessicated. As a consequence, after June 12, the apparent resistivity and phase tensor estimates became increasingly noisy in the 1 to $5 \mathrm{~s}$ period range and occasionally at longer periods. These observations illustrate the challenge of performing continuous MT measurements due to the variability of the Earth's magnetic field and local variations in the degree of coupling of the electrodes. Nevertheless, when the Kp index was large and the electrical coupling was good, the MT tensor estimates at long periods ( $>$ 100s) were consistent from one 4-day time window to the 
other (e.g., between May 29 and June 12). This stability confirms the robustness of the initial MT tensor estimates illustrated in figure 2 as well as the phase tensor parameter estimates.

Long-period MT phase tensor analysis may be implemented to assess the azimuthal variation of the electrical resistivity of a deep regional structure (Booker, 2014). In Mayotte, at a period of approximately $1000 \mathrm{~s}$, the strikes of the phase tensors were approximately $\mathrm{N} 35^{\circ}$ at site $\mathrm{L} 0$ and $\mathrm{N} 41^{\circ}$ at site $\mathrm{L} 2$ (figure 1). This indicates that the deep regional structures in Mayotte are electrically more conductive at orientations of $\mathrm{N} 125^{\circ}$ at site $\mathrm{L} 0$ and $\mathrm{N} 131^{\circ}$ at site $\mathrm{L} 2$; remarkably, these orientations are roughly the same azimuth as the oceanic ridge (Audru et al., 2010).

\section{MT inversion results}

The data recorded at the two land and the four marine MT s tes were jointly inverted to image the electrical resistivity structure beneath Petite Terre islan. W : inverted the four components of the MT impedance tensors at all available periods; in period range for the land MT data was 0.009-1000 s, and that for the marine MT dat? Wau J.02-1000 s. We excluded data with large errors, especially within the dead band. F $r^{t} t_{e}$ 3D inversion, we used the MININ3D code from Hautot et al. $(2000,2007)$. Given the mall number of sites, we used a grid of $21 \times 18 \times 18$ cells which included the bathymetry of the to $\mathrm{v} v$ area. The total volume of the 3D model was 21x20x13 $\mathrm{km}^{3}$. The horizontal dimensions o the cells in the central part of the model is $500 \times 500 \mathrm{~m}$. The thickness of the layers increaseci fron 5 to $5000 \mathrm{~m}$. The 3D model topped a 1D model with three layers with thicknesses of 13,8 and $88 \mathrm{~km}$, whose resistivities were also included in the inversion. Except for the ma ine part (0.3 Ohm.m), the starting model was homogeneous (18 Ohm.m). The 3D inversio I was applied to minimize a misfit function between the observed data and the 3D model response at all sites and frequencies weighted by the data variance. Data were the four complex components of the MT tensor. The starting RMS was 9.3, and the RMS decreased down to 2.2 .

A cross-section through the shallow (until 5km depth) and deep (until 50km depth) section of the 3D resistivity model is shown in figure $\mathrm{S} 2$ and figure 4, respectively. The most prominent feature is the presence of a deep conductive layer (with a resistivity of less than $2 \mathrm{Ohm} . \mathrm{m}$ ) beneath a depth of $13 \mathrm{~km}$ (labelled $\mathrm{C} 1$ on figure 4). A shallow conductive layer (resistivity of less than 5 Ohm.m) is also present within the first $500 \mathrm{~m}$ of the model (labelled C3 on figure S2). Between 
these two conductive structures, the resistivity increases up to $\sim 100$ Ohm.m. Toward the southeast, the resistivity in the $5-13 \mathrm{~km}$ depth range decreases to less than $10 \mathrm{Ohm} . \mathrm{m}$ (labelled C2 on figure 4); this conductor is located close to the hypocenters of the seismic events recorded during the seismovolcanic crisis.

To assess the uncertainties in the deep resistivity structures identified in the 3D resistivity model, we performed a sensitivity analysis on both the resistivity of the conductive layer (below a depth of $13 \mathrm{~km}$ ) and the depth to the top of this conductor (figure 5). The misfit rapidly increases with increasing resistivity below a depth of $13 \mathrm{~km}$, confirming that a conductor of less than 4 Ohm.m is required to fit the data (figure 5a). The optimum depth vi this conductor was found at approximately $16 \mathrm{~km}$ (figure 5b). However, the misfit increas as s owly between this interval indicating that this depth is not very well resolved. We alsn ، ste 1 the sensitivity of the model to the presence of the $\mathrm{C} 2$ conductor between depths of $5 a^{2} .1 \mathrm{~km}$ to the southeast of Petite Terre and on the edge of the MT network (figure 4). The a sence of this conductor significantly increased the misfit (figure $5 \mathrm{c}$ ), suggesting that $\mathrm{t}$ is f sature was not an artifact of the inversion process and was constrained by the MT dat?

\section{Discussion}

In this section, we discuss the electac ${ }^{1}$ resistivity structure of the Petite Terre island derived from the inversion of the MT data anc propose an interpretation of the geoelectric structure of the island (figure 6).

The presence of a sha low conductive layer overlying a more resistive body beneath the surface of Petite Terre ( 1 belled C3 in figure S2) is consistent with the electrical resistivity structure typically observed under volcanoes exhibiting well-developed hydrothermal systems (Flóvenz et al., 2005; Ussher et al., 2000). According to these models, this shallow conductive layer (resistivity of 1-10 Ohm.m) corresponds to a smectite-rich, low-temperature $\left(<220^{\circ} \mathrm{C}\right)$, hydrothermally altered layer, often called a clay cap. For Petite Terre, this layer would be approximately $500 \mathrm{~m}$ thick. At greater depth and with increasing temperature $\left(>220^{\circ} \mathrm{C}\right)$, the material is less rich in smectite, whereas the illite content increases. Furthermore, porosity tends to decrease with depth, which reinforces the modeled resistivity increase due to the change in alteration products (Ussher et al., 2000) with resistivity values ranging from 20 to 100 Ohm.m. On 
Petite Terre, such values are observed below depths of $500 \mathrm{~m}$ and deeper and could correspond to a high-temperature geothermal reservoir.

At depths of 13-16 km, the resistivity drops by almost two orders of magnitude, reaching values of a few Ohm-meters (labelled $\mathrm{C} 1$ on figure 4). At such depths, the temperature is very likely to exceed $450{ }^{\circ} \mathrm{C}$, which is the estimated temperature at a depth of $15 \mathrm{~km}$ for a normal geothermal gradient of $30^{\circ} \mathrm{C} / \mathrm{km}$ (Saemundsson et al., 2009). The electrical signature of rocks under such high-temperature conditions is still not fully understood, but recent laboratory experiments (Kummerow and Raab, 2015b,a; Nono et al., 2018) have shown that at $25-350^{\circ} \mathrm{C}$, the resistivity of altered volcanic rock decreases as a result of both incicising surface and electrolytic conduction. Then, under supercritical conditions, i.e., at tempera. 'Ires of $400-600^{\circ} \mathrm{C}$, the electrical resistivity strongly increases due to the evolution of the $\mathrm{v}_{\mathrm{v}}$ ter lensity and dielectric constant, which affect both surface and electrolytic conduction. $A^{+\cdots} g_{1}$. or temperatures $\left(>600^{\circ} \mathrm{C}\right.$ ), mineral conduction dominates the resistivity of the rock; at thest -mperatures, ferromagnesian minerals serve as the principal contributors of mineral cr nr.ution, resulting in a decrease in the rock resistivity. At even higher temperatures $\left(1000^{\circ} \mathrm{C}\right.$ ), partial melting may occur, thereby decreasing the rock resistivity further ( $\mathrm{La}$ - nonier et al., 2017). The low resistivities (a few Ohm-meters) observed throughout Petitc Terre at depths of 13-16 km could therefore be caused either by the presence of altered rocks s 'th a ated with fluid below the supercritical point $\left(<400^{\circ} \mathrm{C}\right)$ or by the presence of a small fracti in oi connected melt. At these depths, the temperature exceeds the supercritical point; hence, he nost likely explanation for the observed conductive layer is the presence of melt. Similar hse." ations have been reported beneath oceanic ridges on the basis of MT soundings (Baba $\left.\imath^{+} a_{2}^{\prime}, 2006\right)$ and interpreted as being indicative of the presence of melt (Laumonier et al., 2017, : : his hypothesis is further supported by the good correlation between the electrical strike of the observed phase tensors (figure 1) and the azimuth of the oceanic ridge (Audru et al., 2010). Nevertheless, additional laboratory data (e.g., electrical resistivity measurements on Mayotte volcanic rock samples) and geophysical observations (e.g., imaging of zones characterized by low seismic velocities) are necessary to confirm this interpretation.

Finally, we noticed the presence of a conductive structure in the $5-15 \mathrm{~km}$ depth range to the southeast of Petite Terre (labelled C2 on figure 4) close to the seismic events recorded between May 2018 and May 2019. In this area, recent volcanic material and gas emissions have been observed on the seafloor (REVOSIMA bulletins, www.ipgp.fr/fr/actualites-reseau). Accordingly, 
this conductive anomaly could be related to recent seismovolcanic activity. Additional deep marine MT sites are currently being deployed in this area to obtain more insight into the presence and geometry of this conductive anomaly and its relationship with the regional seismovolcanic activity. Furthermore, the two permanent land stations at sites L0 and L2 are currently being maintained to perform robust-processing of the deep marine MT sites but also long-term monitoring of any resistivity changes at depth related to the evolution of the seismovolcanic crisis.

\section{Conclusions}

Since May 2018, a major seismovolcanic crisis has affected the is ran's of Mayotte in the Comoros Archipelago, providing a unique opportunity to monitor the de elopment of an active volcanic system. Preliminary MT data acquired on and near this 1s' and were implemented to image the electrical resistivity structure of the volcanic system. Thi res lting model suggests the presence of hydrothermal fluids in the shallow part of the sys $\ldots n(<2 \mathrm{~km})$ and magmatic fluids at greater depth (> $15 \mathrm{~km}$ ). Further petrophysical and gec hyvical studies (e.g. additional land and offshore MT surveys, seismic surveys) are ongoi $\sigma \dagger \jmath$ confirm the origin and geometry of these deep conductors and to help better unders and the associated magmatic and volcanic activity. In addition, the permanent land MT sta $1 c_{1 .} \mathrm{S}$ are currently being maintained to perform long-term monitoring of any resistivity chans es it uepth related to the evolution of the seismovolcanic crisis.

\section{Acknowledgments}

We would like to thank $l_{1} \cdot$ Mayotte branch of the Environment and Energy Management Agency (ADEME) and the General Directorate for Risk Prevention (DGPR) for financially supporting the geophysical work, the staff from the French Geological Survey (BRGM) office in Mayotte for providing logistical support during the MT survey, and the RÃ@seau de Surveillance Volcanologique et Sismologique de Mayotte (REVOSIMA) for coordinating the geoscientific efforts during the seismovolcanic crisis. The French Hydrographic Office (SHOM) provided the bathymetry used in the MT inversion. Data are available on the data repository 4TU.Centre for Research Data (https://doi.org/10.4121/uuid:cb760562-3d5f-43fd-b2b1-1612894ab0ec). 


\section{References}

Abdelfettah, Y., Sailhac, P., Larnier, H., Matthey, P.D., Schill, E., 2018. Continuous and time-lapse magnetotelluric monitoring of low volume injection at rittershoffen geothermal project, northern alsace-france. Geothermics 71, 1-11.

Aizawa, K., Koyama, T., Uyeshima, M., Hase, H., Hashimoto, T., Kanda, W., Yoshimura, R., Utsugi, M., Ogawa, Y., Yamazaki, K., 2013. Magnetotelluric and temperature monitoring after the 2011 sub-plinian eruptions of shinmoe-dake volcano. Earth, Planets and Space 65, 6.

Audru, J.C., Bitri, A., Desprats, J.F., Dominique, P., Eucher, G., Inchi'm, S., Jossot, O., Mathon, C., Nédellec, J.L., Sabourault, P., et al., 2010. Major n.trlı 'tazards in a tropical volcanic island: a review for mayotte island, comoros archip laz =, Indian ocean. Engineering geology 114, 364-381.

Baba, K., Chave, A.D., Evans, R.L., Hirth, G., Mackie R.L 2006. Mantle dynamics beneath the east pacific rise at $17 \mathrm{~s}$ : Insights from the $n \cdot n t^{1} \approx$ electromagnetic and tomography (melt) experiment. Journal of Geophysica' Re eaı.h: Solid Earth 111.

Booker, J.R., 2014. The magnetotelluric phase tensor: a critical review. Surveys in Geophysics 35, $7-40$.

Cesca, S., Letort, J., Razafindrakotr $H^{\circ}$ ^., 2020. Drainage of a deep magma reservoir near mayotte inferred from se smi-ity and deformation. Nature Geoscience 13, 87-93.

Chave, A.D., Jones, A.G., 201'2. The magnetotelluric method: Theory and practice. Cambridge University Press.

Chave, A.D., Thomson, L J., 2004. Bounded influence magnetotelluric response function estimation. Geopnysical Journal International 157, 988-1006.

Debeuf, D., 2004. Étude de l'évolution volcano-structurale et magmatique de mayotte (archipel des comores, océan indien). Université de la Reunion, 277.

Egbert, G.D., 2002. Processing and interpretation of electromagnetic induction array data. Surveys in geophysics $23,207-249$.

Emerick, C., Duncan, R., 1982. Age progressive volcanism in the comores archipelago, western indian ocean and implications for somali plate tectonics. Earth and Planetary Science Letters 60, 415-428.

Flóvenz, Ó., Spangenberg, E., Kulenkampff, J., Árnason, K., Karlsdóttir, R., Huenges, E., 2005. 
The role of electrical interface conduction in geothermal exploration, in: Proceedings of the 2005 world geothermal congress, pp. 24-29.

Hautot, S., Single, R., Watson, J., Harrop, N., Jerram, D., Tarits, P., Whaler, K., Dawes, D., 2007. 3-d magnetotelluric inversion and model validation with gravity data for the investigation of flood basalts and associated volcanic rifted margins. Geophysical Journal International $170,1418-1430$.

Hautot, S., Tarits, P., Whaler, K., Le Gall, B., Tiercelin, J.J., Le Turdu, C., 2000. Deep structure of the baringo rift basin (central kenya) from three-dimensional magnetotelluric imaging: Implications for rift evolution. Journal of Geophysical Resta. h: Solid Earth 105, 23493-23518.

Ingham, M., Bibby, H., Heise, W., Jones, K., Cairns, P., Draı itzk , S., Bennie, S., Caldwell, T., Ogawa, Y., 2009. A magnetotelluric study of me..t 1 apehu volcano, new zealand. Geophysical Journal International 179, 887-904.

Junge, A., 1996. Characterization of and correctio If Jr cultural noise. Surveys in Geophysics 17, 361-391.

Kummerow, J., Raab, S., 2015 a. Temperatı $\div$ dependence of electrical resistivity-part ii: A new experimental set-up to study fluic saturated rocks. Energy Procedia 76, 247-255.

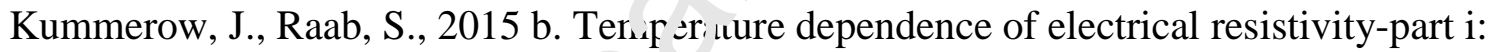
Experimental investigation of ıydrothermal fluids. Energy Procedia 76, 240-246.

Ladanivskyy, B., Zlotnicki, J., Re. iva, P., Alanis, P., 2018. Electromagnetic signals on active volcanoes: Analysic n al etrical resistivity and transfer functions at taal volcano (philippines) res. te ${ }^{1}$ 's the 2010 seismovolcanic crisis. Journal of Applied Geophysics 156, $67-81$.

Laumonier, M., Farla, R., Frost, D.J., Katsura, T., Marquardt, K., Bouvier, A.S., Baumgartner, L.P., 2017. Experimental determination of melt interconnectivity and electrical conductivity in the upper mantle. Earth and Planetary Science Letters 463, 286-297.

Lemoine, A., Bertil, D., Roullé, A., Briole, P., 2019. The volcano-tectonic crisis of 2018 east of mayotte, comoros islands.

Michon, L., 2016. The volcanism of the comoros archipelago integrated at a regional scale, in: Active volcanoes of the southwest Indian Ocean. Springer, pp. 333-344.

Nono, F., Gibert, B., Parat, F., Loggia, D., Cichy, S.B., Violay, M., 2018. Electrical conductivity 
of icelandic deep geothermal reservoirs up to supercritical conditions: Insight from laboratory experiments. Journal of Volcanology and Geothermal Research.

Nougier, J., Cantagrel, J., Karche, J., 1986. The comores archipelago in the western indian ocean: volcanology, geochronology and geodynamic setting. Journal of African Earth Sciences 5, 135-145.

Revil, A., Cathles, L., Losh, S., Nunn, J., 1998. Electrical conductivity in shaly sands with geophysical applications. Journal of Geophysical Research: Solid Earth 103, 23925-23936.

Saemundsson, K., Axelsson, G., Steingrmsson, B., 2009. Geothernia' systems in global perspective. Short Course on Exploration for Geothermat Res jurces, UNU GTP 11.

Smai, F., Wawrzyniak, P., 2020. Razorback, an open source 1 th th $^{\prime}$ library for robust processing of magnetotelluric data. Front. Earth Sci 8, 296.

Spichak, V., Manzella, A., 2009. Electromagnetic soundı - of geothermal zones. Journal of Applied Geophysics 68, 459-478.

Ussher, G., Harvey, C., Johnstone, R., Ande _. vn, E., 2000. Understanding the resistivities observed in geothermal systems, in: $;$ oceedings world geothermal congress, Kyushu. pp. 1915-1920.

Wawrzyniak, P., Zlotnicki, J., Sailhac, '`, , iMarquis, G., 2017. Resistivity variations related to the large march 9, 1998 erupti $\urcorner$ at ia fournaise volcano inferred by continuous mt monitoring. Journal of Volcanolog, an ${ }^{\top}$ Geothermal Research. 
Figure 1: Left: geodynamic context of the Mayotte island, after Lemoine et al. (2019). Right: location of the MT stations deployed onshore and offshore Petite Terre island. The blue triangles represent the MT sites. The green circles represent the epicenters of the seismic events recorded from May 2018 to May 2019, after Lemoine et al. (2019). The red ellipses with an arrow represent the phase tensor ellipses at $1000 \mathrm{~s}$ at sites $\mathrm{LO}$ and L2. Profile $\mathrm{AA}^{\prime}$ ' is the location of the cross-section through the 3D resistivity model in Figure 4.

Figure 2: MT soundings for sites L2 (left panel) and M2 (right pa nel). The upper and lower panels display the apparent resistivity in $\Omega . m$ and phase in ' 'eg) ees, respectively. The full lines signify the responses of the best-fitting model.

Figure 3: Site L2. Four-day time-lapse remote referenc processing results between May $29^{\text {th }}$ and June $28^{\text {th }}$. (a) Three-hour Kp index, (b) p ' case tensor ellipses filled with the determinant apparent resistivity on a $\log _{10}, \mathrm{cai} \cdot$ and (c) successive 4-day interval estimates of the apparent resistivity components $\mathrm{xy}$, Ipper left) and $\mathrm{yx}$ (upper right) and phase components xy (lower left) and yx (lowe w right).

Figure 4: $\mathbf{N 1 2 0}^{\circ}$ cross-section thr igh the 3D resistivity volume obtained from the inversion of the land and marine MT a. ta. Green circles represent the hypocenters of the seismic events recorded from $M_{* y}$ 1, ¿J18, to May 28, 2019 (Lemoine et al., 2019). Yellow triangles represent the MT sites 'ssu in the MT inversion.

Figure 5: Variation of the misfit between the tested and preferred model as a function of a) the resistivity of the deep conductive layer, $b$ ) the depth of the top of this conductor and c) the presence of a conductor between 5 and 13km depth to the South-East of Petite Terre. The value 0 corresponds to the preferred model.

Figure 6: Electrical resistivity structure of the Petite Terre island derived from inversion of the MT data and proposed interpretation of the geoelectric structure. 
Credit Authors

Darnet M.: supervision, funding acquisition, resources, investigation, writing original and review Wawrzyniak P.: investigation, software, writing original and review

Tarits P.: investigation, software, resources, writing original and review

Hautot P.: investigation, software, writing original and review

D’Eu J.F.: investigation, resources, software 


\section{Declaration of interests}

$\bigotimes$ The authors declare that they have no known competing financial interests or personal relationships that could have appeared to influence the work reported in this paper.

$\square$ The authors declare the following financial interests/personal relationships which may be considered as potential competing interests:

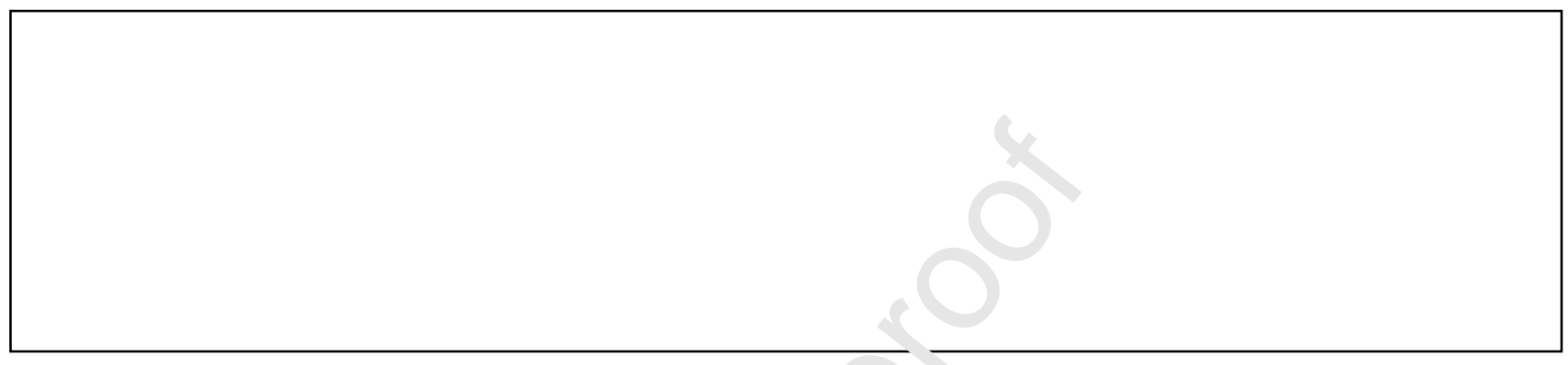


Highlights

- A major seismovolcanic crisis has afflicted the islands of Mayotte, Comoros Archipelago, since May 2018, although the origin is debated.

- We report the results of a preliminary land and shallow marine MT survey performed on and offshore the island nearest the crisis.

- The 3D inversion-derived electrical resistivity model suggests that the island is underlain by a shallow 500-m-thick conductive layer atop a deeper, more resistive layer, possibly associated with a high-temperature geothermal system.

- At depths of $\sim 15 \mathrm{~km}$, the resistivity drops by almost two orders of magnitude, possibly due to partial melting. 

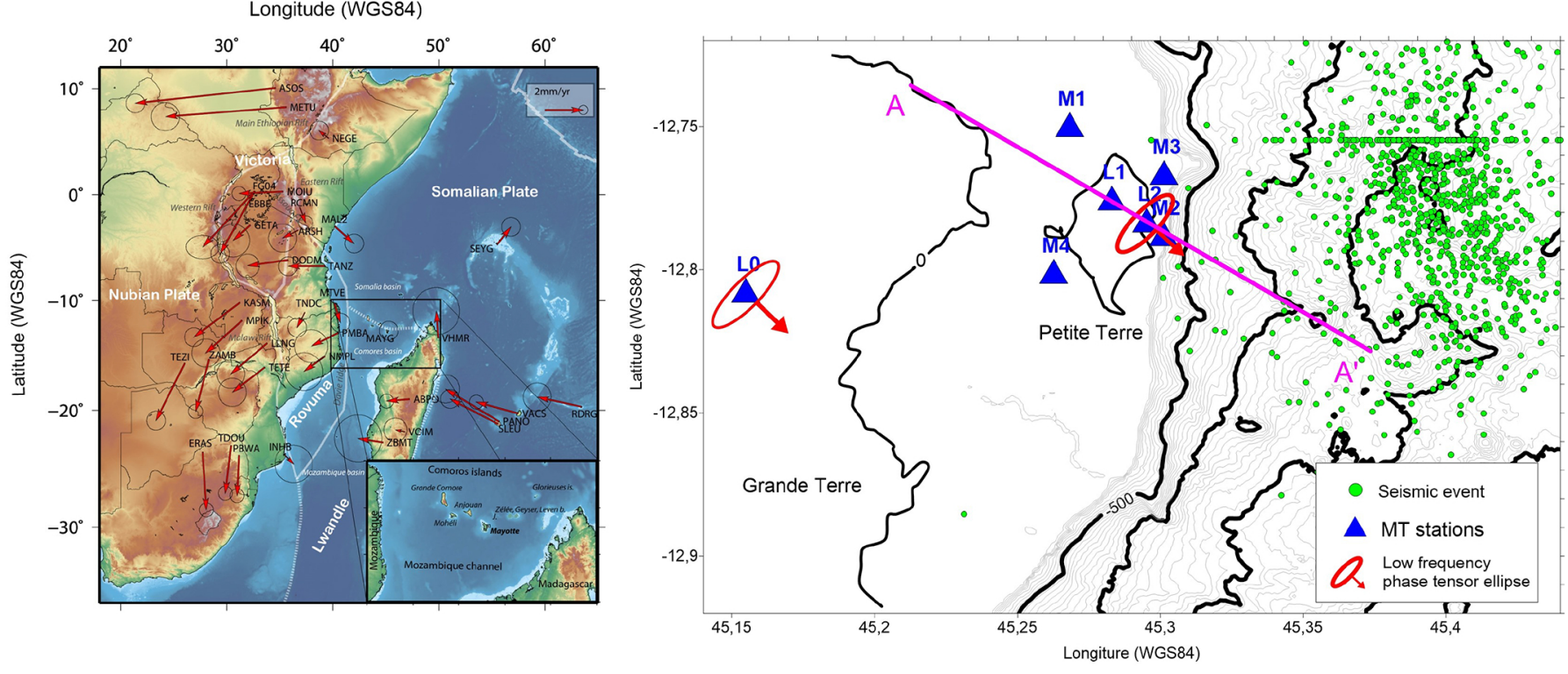

Figure 1 
L2
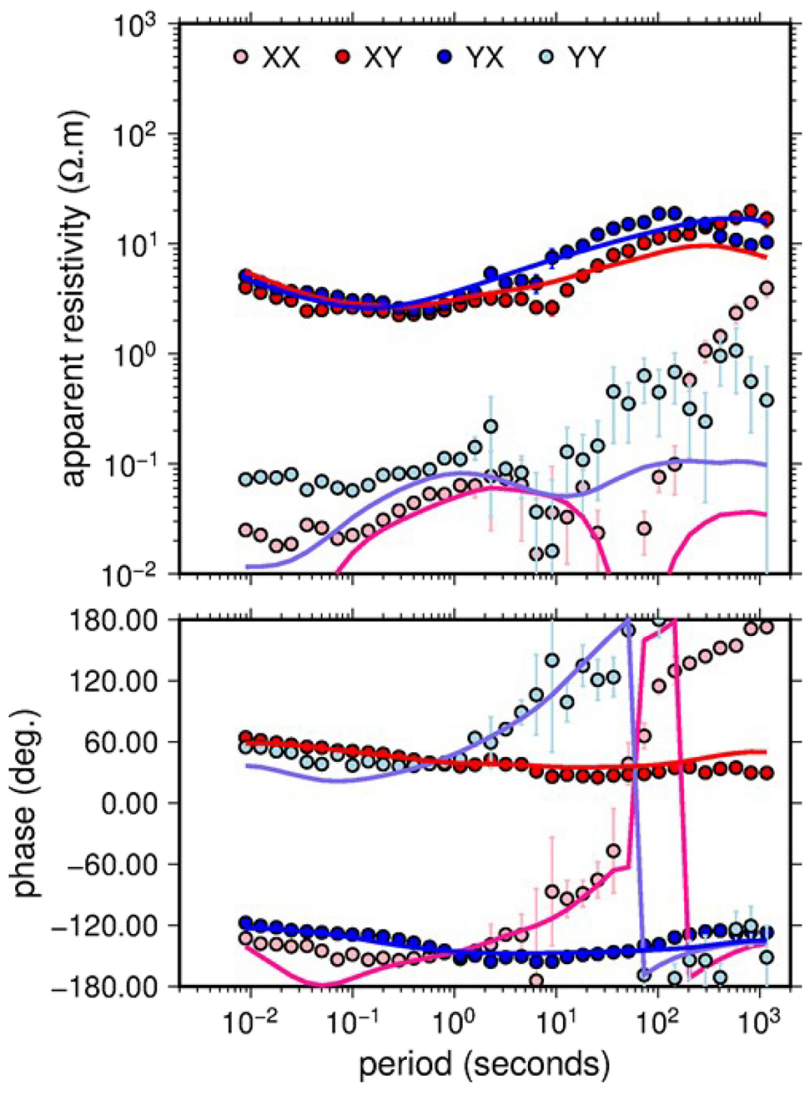

M2
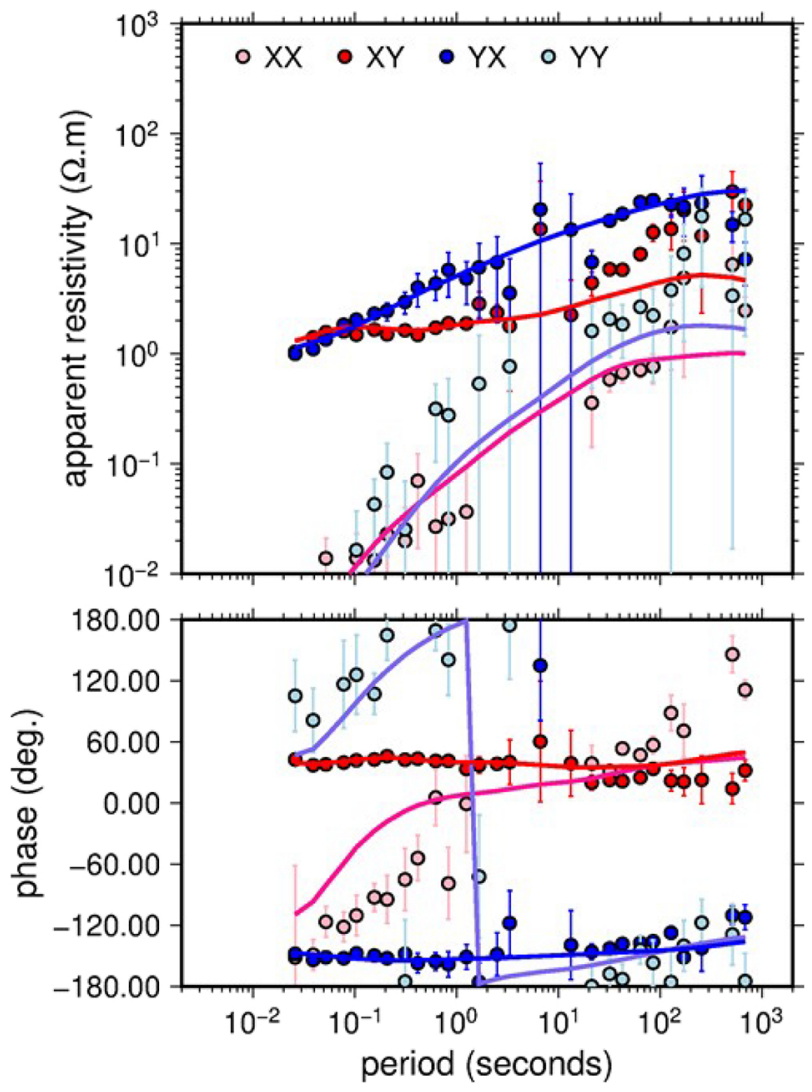
a)

b) 


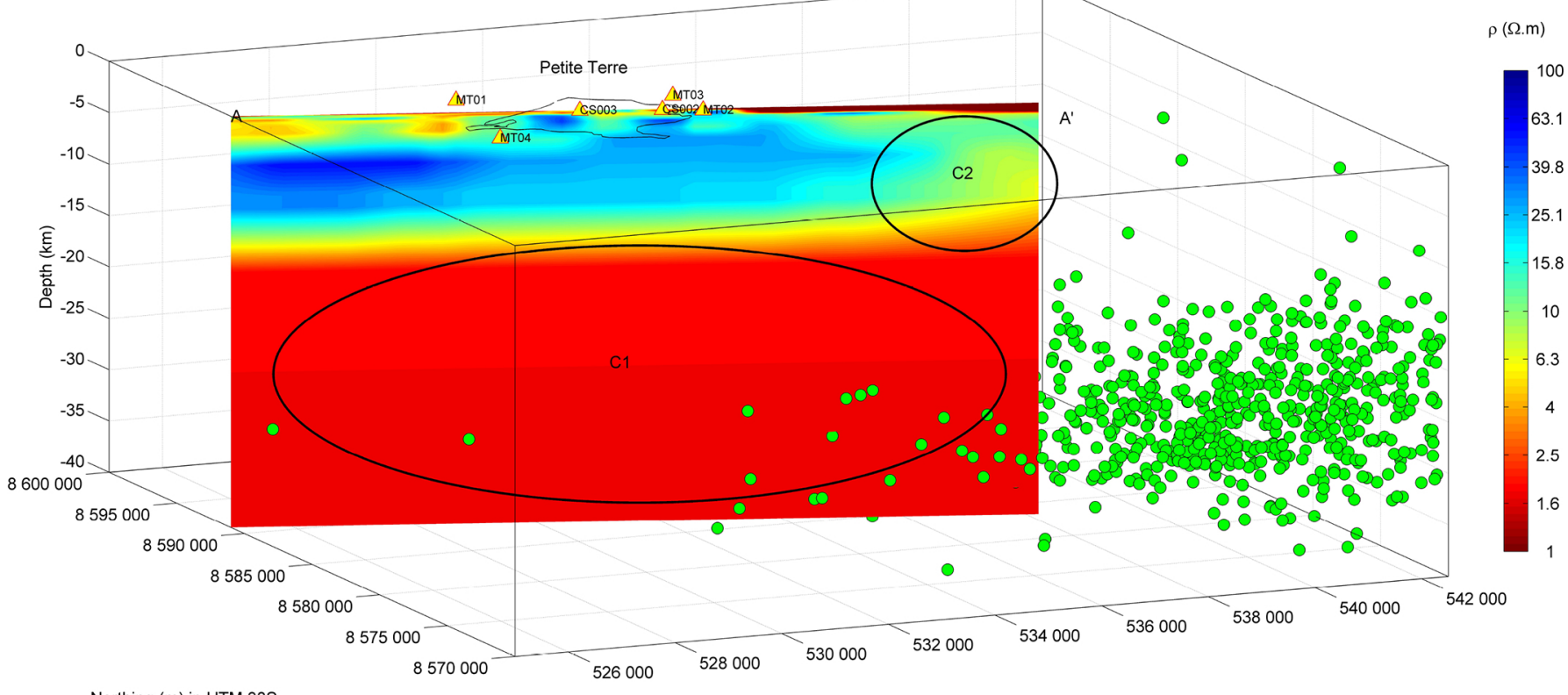
Northing (m) in UTM $38 \mathrm{~S}$ 

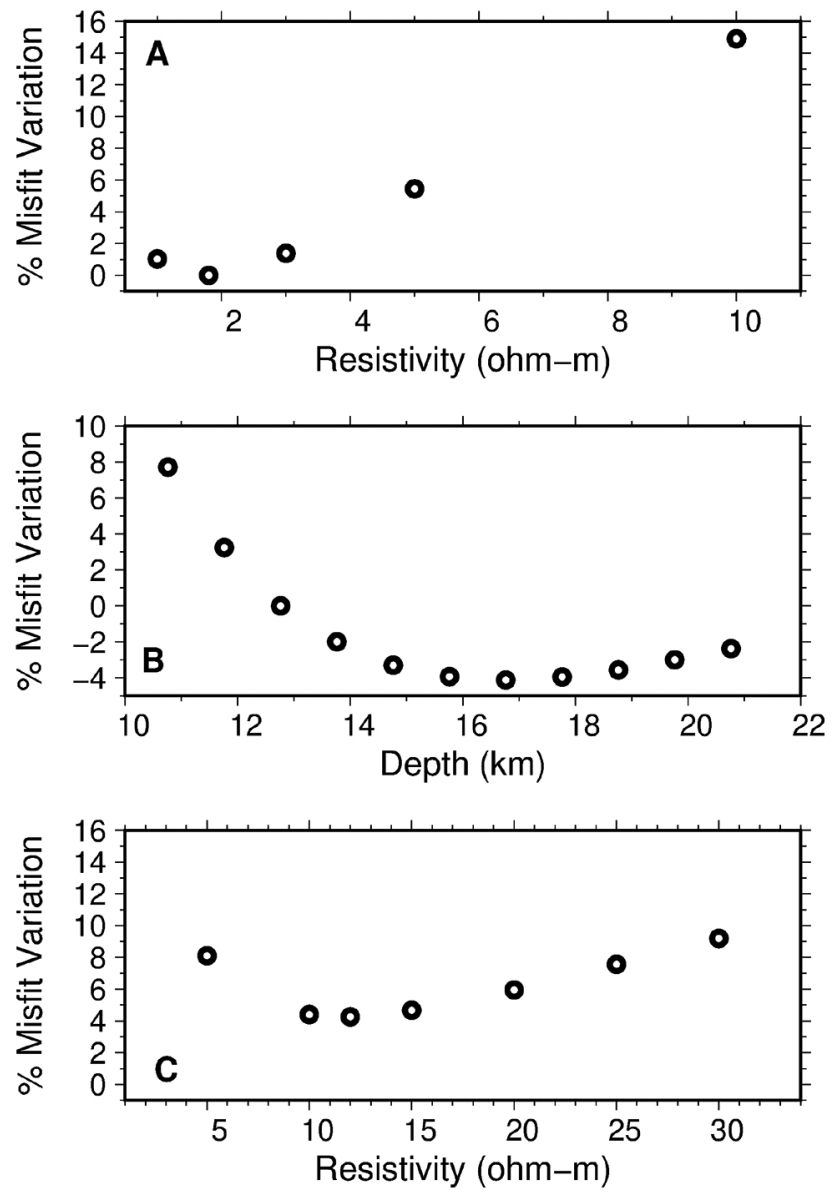

Figure 5 


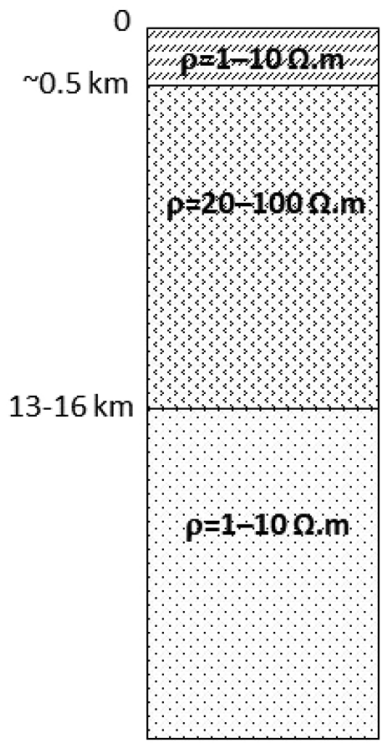

Smectite-rich, low-temperature $\left(<220^{\circ} \mathrm{C}\right)$, hydrothermally altered layer (clay cap)

\author{
Illite-rich, high-temperature \\ $\left(>220^{\circ} \mathrm{C}\right)$, hydrothermally altered \\ layer (geothermal reservoir?) \\ then low porosity material (crust)
}

Presence of melt?

Figure 6 